\title{
The Alliance for Innovation in Maternal Care: A National Partnership to Improve Maternal Safety
}

\author{
Jeanne Mahoney* \\ Senior Director, Providers' Partnership and AIM Program American College of Obstetricians and Gynecologists, USA
}

Submission: May 24, 2018; Published: August 09, 2018

*Corresponding author: Jeanne Mahoney, Senior Director, Providers' Partnership and AIM Program American College of Obstetricians and Gynecologists, 409 12th St. SW, Washington, DC 20024, USA, Tel: 202-314-2352; Email: jmahoney@acog.org

Keywords: Gynecologists; Advocacy organizations; Risk maternal conditions; Venous thromboembolism; Vaginal births; Maternal safety; Warning signs; Morbidity; Midwifery; Obstetric care of women; Participating hospitals; Maternal morbidity

\section{Introduction}

Responding to a disturbingly rising maternal mortality rate in the U.S, a national partnership of provider, public health and advocacy organizations, administrated by the American College of Obstetricians and Gynecologists, developed the Alliance for Innovation on Maternal Health (AIM). AIM aligns national, state, and hospital level efforts to improve maternal health and safety and is poised to reduce severe maternal morbidity by 100,000 events and maternal mortality by 1,000 deaths by 2018 . With funding received from the Health Resource Services Administration, AIM provides evidence-based front-line resources for birth facilities and provider/public health teams to adapt and implement a series of action steps (bundles) on high risk maternal conditions. AIM support harmonized data-driven, rapid-cycle, continuous quality improvement processes to engage providers and birth facilities. Starting with states that have high rates of maternal mortality, AIM utilizes a broad variety of partners to develop state level teams for bundle implementation.

\section{Short Communication}

Bundles are standardized evidence-informed processes to reduce variation in response to maternal care. They are developed by multidisciplinary work groups of experts in the field representing each of our Alliance partners and specialty organizations.

\section{Below is the current listing of bundles completed or un- derway.}

I. Severe hypertension/Preeclampsia

II. Obstetric hemorrhage

III. Prevention of maternal venous thromboembolism
IV. Safe reduction of primary cesarean births/supporting intending vaginal births

V. Reduction of peripartum racial disparities

VI. Postpartum care basics for maternal safety (first 6 weeks)

VII. Transition to well woman care ( 6 weeks to 1 year)

VIII. Patient, family and staff support

IX. Obstetric care of women with opioid use disorder.

\section{Bundle tools include}

i. Maternal early warning signs

ii. Reporting forms for severe maternal morbidity

The Alliance partners are national organizations ready to share their expertise and guide the AIM program (Table 1). AIM works through state teams. These teams must have a leader; be able to provide deidentified hospital administrative data quarterly to the AIM data center; engage state public health officers; conduct multidisciplinary maternal mortality review reviews and identify champions among nursing, midwifery, and physicians. AIM is a data driven quality improvement initiative. The AIM team has identified low burden metrics for measuring bundle adoption and maternal outcomes within states and hospitals implementing the bundles. Deidentified outcome, structure and process data reported to the AIM data center, is benchmarked with other similar hospitals within states and networks and reported back to the participating hospitals and states. Hospitals and states are guided to actively use the data for quality improvement. 
Table 1:

\begin{tabular}{|c|}
\hline The AIM Alliance \\
\hline Am. College of Obstetricians and Gynecologists \\
\hline Am. College of Nurse Midwives \\
\hline Am. Academy of Family Practitioners \\
\hline Am. Society of Healthcare Risk Management \\
\hline Am. Society for Addiction Medicine \\
\hline Assoc. of Maternal and Child Health Programs \\
\hline Assoc. of State and Territorial Health Officers \\
\hline Assoc. of Women's Health, Obstetric and Neonatal Nurses \\
\hline Black Mamas Matter \\
\hline Every Mother Counts \\
\hline Genetic Alliance \\
\hline Healthy Start \\
\hline March of Dimes \\
\hline National Institute for Children's Health Quality \\
\hline National Perinatal Information Center \\
\hline National WIC Assoc. \\
\hline Nurse Practitioners for Women's Health \\
\hline Preeclampsia Foundation \\
\hline Premier, Inc. \\
\hline Society for Obstetric Anesthesia and Perinatology Health Care \\
\hline
\end{tabular}

The AIM team develops, identifies and provides an increasing number of resources for hospitals and state teams to implement the Maternal Safety Bundles. These include online, interactive and brief learning modules for staff education; check lists; work plans; direct links to tool kits and other published resources. The AIM website (www.safehealthcareforeverywoman) holds these resources and provides assistance with data management, and a contact/help center. AIM participants from hospitals and state teams are encouraged to engage in monthly calls with other states and hospital network participants as learning communities. AIM has developed a 14-state collaborative to identify the national metrics and resources required to implement the AIM bundle: Obstetric care of women with opioid use disorder. AIM is continually reviewing and revising resources for implementation and growth. All resources are open access and can be shared freely.

AIM supports participants by offering Part IV maintenance of certification for physicians and offer CEUs for nurses utilizing the online modules. AIM is developing an award program for participating hospitals. AIM programs in low resource U.S. settings and countries are dramatically proving the basic concepts of AIM. Dedicated, health care professionals of multiple disciplines and training levels use the AIM bundles and work in concert to reduce barriers and improve communication to reduce maternal mortality and severe morbidity. And though only 3 years since development, AIM is showing significant reduction in the rate of severe maternal morbidity ( 7.8 to $22 \%$ decrease) within the 5 states that began bundle implementation in 2015. Below are the States currently engaged in AIM (Table 2). At the time of publication another 13 states have indicated interest to enroll in AIM.

\section{Table 2:}

\begin{tabular}{|c|c|c|}
\hline Oklahoma & New Jersey & North Carolina \\
\hline Louisiana & Illinois & Utah \\
\hline Maryland & Florida & California \\
\hline Michigan & Georgia & West Virginia \\
\hline Mississippi & Tennessee & Texas \\
\hline New York & Virginia & South Carolina \\
\hline AIM Networks & Other AIM Settings \\
\hline \multicolumn{2}{|c|}{ Trinity Healthcare } & Malawi \\
\hline \multicolumn{2}{|c|}{ Premier, Inc. } & No. Mariana Islands \\
\hline \multicolumn{2}{|c|}{ National Perinatal Information Center } & Indian Health Service \\
\hline
\end{tabular}

\section{Your next submission with Juniper Publishers will reach you the below assets}

- Quality Editorial service

- Swift Peer Review

- Reprints availability

- E-prints Service

- Manuscript Podcast for convenient understanding

- Global attainment for your research

- Manuscript accessibility in different formats

( Pdf, E-pub, Full Text, Audio)

- Unceasing customer service

Track the below URL for one-step submission https://juniperpublishers.com/online-submission.php 